\title{
痴呆患者の予後と脳血流量, 脳萎縮との関連について
}

\author{
岡田 和悟 小林 祥泰 山口修平 木谷 光博 \\ 有元佐多雄 下手 公一勝部 知子 恒松徳五郎
}

\begin{abstract}
＜要 旨＞ 痴呆患者の予後は不良であり， 5 年後の死亡率はほぼ $80 \%$ と報告されている。 また，痴呆 患者の脳血流量低下の経過はその病型によって異なることが報告されている，我々はすでに痴呆患者の $\mathrm{CT}$ 上の脳萎縮と ${ }^{133} \mathrm{Xe}$ 吸入法による脳血流量を同時に検討し, 痴呆の程度に対するとれらの関係が病型 により異なることを報告してきた。今回は，上記についてすでに検討した35例の痴呆患者（多発梗塞性 痴呆 (MID) 22例，アルッハイマー型痴呆 (DAT) 13例) の平均 18 カ後（ 3 × 48月）の予後調查を 行った.

[結果］1）調查期間中にDAT では13例中 3 例が，MID では22例中 8 例が死亡した，2）DAT に拀い ては, 死亡例は生存例に比し有意に高齢であった，3）DAT の悪化，死亡群は不変群に比し有意に脳萎 縮が強く，また両側頭頂葉で不変群に比し有意な脳血流量低下が認められた。4）MID では死亡例で生存 例（悪化十不変群）に比し有意な全脳血流量低下が認められたが，脳萎縮に差はみられなかった．以上 より痴呆の予後と脳血流量, 脳萎縮の関係は病型により異なることが示唆された。
\end{abstract}

Key words : 痴呆の予後, アルッハイマー型痴呆, 多発梗塞性痴呆, 脳萎縮, 脳血流量

\section{緒言}

痴呆患者の予後に関しては Goldfarb ${ }^{1)}$, Nielsen ${ }^{21}$, $\mathrm{Kay}^{3)}$ らの報告がみられるが, 我が国に怙いては長谷 川ら (4)報告がみられるのみである。これらの報告で は 5 年後の死亡率は $73 \sim 87.4 \%$ あるとして打り，そ の予後は不良であることが知られている。長谷川らに よれば, 高度痴呆, 失禁, 寝たさりの要因により死亡 率が増加するとされている。 また痴呆患者の予後は痴 呆の大半を占める二つの病型即ちアルッハイマー型痴 呆 (以下 DAT と略す) と多発梗塞性痴呆（以下 MID と略す）に分けて検討しても変らないとされている. しかし近年, Barclay ら5は MID が DAT に比べ死亡 率が高いと報告している。亦た痴呆患者の発症前から 脳血流量の変化を追跡した Rogers ら ${ }^{6}$ は痴呆の病型 によりそのパターンは異なるとしている。我々はこれ までに痴呆患者の脳萎縮と脳血流量を同時に検討し， 痴呆の程度とそれらの関係が病型により異なることを 報告7)してきた. 今回, 35例の痴呆患者について平均 18 カ月後の予後調査を行い, 痴呆の予後と脳血流量, 脳

K. Okada, S. Kobayashi, S. Yamaguchi, M. Kitani, S. Arimoto, K. Shimode, T. Tsunematsu : 島根医 科大学第三内科

受付日. 1986.10.20.
萎縮の関係について病型別に検討した。

\section{対 象}

臨床症状, Hachinski の Ischemic score ${ }^{8)}$, CT ス キャン等によりDSM III に準じて診断したアルッハ イマー型痴呆 13 例 (男 6 例, 女 7 例, 初診時平均 67 歳) および多発梗塞性疾呆 22 例 (男 15 例, 女 7 例, 同72歳) の計35例を対象とした。追跡期間は 3-48力月, 平均 18カ月である.いずれも初診時, 独歩可能な初期から 中期の痴呆患者で， 4 例が老人ホーム入所ないし入院 例であり，他はすべて家庭介護例である. MID に関し ては, 脳萎縮を定量化するため, 皮質梗塞例は除外し た。

\section{万法}

1）知的精神機能の評価：言語性知能の指標として 長谷川式簡易知的機能診査スケールを, 日常生活動作 障害度の指標として Hachinski の ADL スコア いた。

2）脳萎縮の評価：初診時の CTフィルムで, 既に報 告した ${ }^{9)}$ digitizer 用いた二次元的な脳萎縮度 (Brain Atrophy Index : BAI）を測定した（図 1)。これまで の検討より, 脳萎縮の指標としては松果体を通る基底 核レベルでのBAIを用いた。 


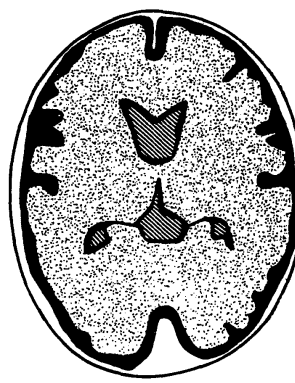

$V A I=V /(V+B)$ $B A I=B /(V+B+S)$

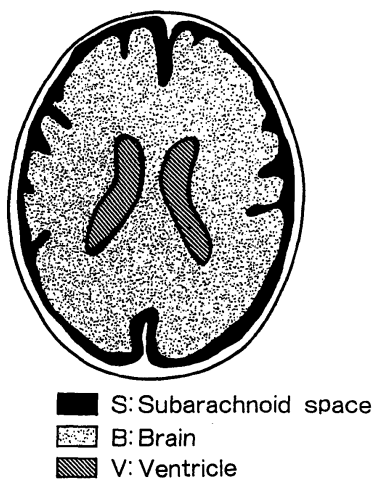

S:Subarachnoid space $\mathrm{V}$ : Ventricle
図 1 Digitizer 法による脳萎縮の定量的評価法. 脳実 質/頭蓋内断面積比（BAI）と脳室／脳断面積比 （VAI）の測定法.

3）局所脳血流量：初診時 ${ }^{133} \mathrm{Xe}$ 吸入法により, 16chNOVO-Cerebrograph にて測定し Fourier解析を用 いて皮質血流量（F1 值）を算出した。

4）予後調査：全例を臨床症状の変化により, ほぼ不 変群, 悪化群, 死亡群の 3 群に分類した. 外来通院例 以外については電話によるアンケート調査を行った。

得られた結果の統計学的検定にはStudent's t test を用いた。

\section{結果}

1）予後：表 1 に示すようにアルッハイマ一型痴呆 (DAT) では 13 例中不変 7 例, 悪化 3 例, 死亡 3 例であ り, 一方多発梗塞性痴呆 (MID) では各々 11 例， 3 例, 8 例であった. DAT の 3 例の死因はそれぞれ肺炎, 心 臓疾患, 突然死各 1 例であった. MID では 8 例中, 脳 血管障害再発 2 例, 肺炎 2 例, 腎不全, 悪性腫瘍各 1 例，不詳 2 例であった。

年齢別に検討すると図 2 に示すようにDAT に招い て死亡群 $(79.7 \pm 12.7$ 歳) は生存群 (不変十悪化) (62.7士6.9歳)に比し有意に高齢であった. MID では 3 群間に年齢による相違はみられなかった。また発症

表 1 アルッハイマー型痴呆 (DAT) と多発梗塞性 痴呆 $(\mathrm{MID})$ )予後と脳血流量 $(\mathrm{rCBF})$ 及び脳萎 縮度 (BAI)

\begin{tabular}{c|r|c|c|c|c|c}
\hline & 不変 & 悪化 & 死亡 & 計 & $\begin{array}{c}\text { 初診時 } \mathrm{rCBF} \\
\mathrm{m} l / 100 \mathrm{~g} / \mathrm{min}\end{array}$ & $\begin{array}{c}\text { 初診時 } \mathrm{BAI} \\
\%\end{array}$ \\
\hline $\mathrm{DAT}$ & 7例 & 3例 & 3例 & 13例 & $57.5 \pm 15.4^{*}$ & $78.4 \pm 6.3 \#$ \\
\hline $\mathrm{MID}$ & 11例 & 3例 & 8例 & 22 例 & $50.4 \pm 9.8^{*}$ & $79.8 \pm 4.3 \#$ \\
\hline \multicolumn{6}{c}{${ }^{*} \mathrm{p}<0.02 \quad$ \#no significant }
\end{tabular}

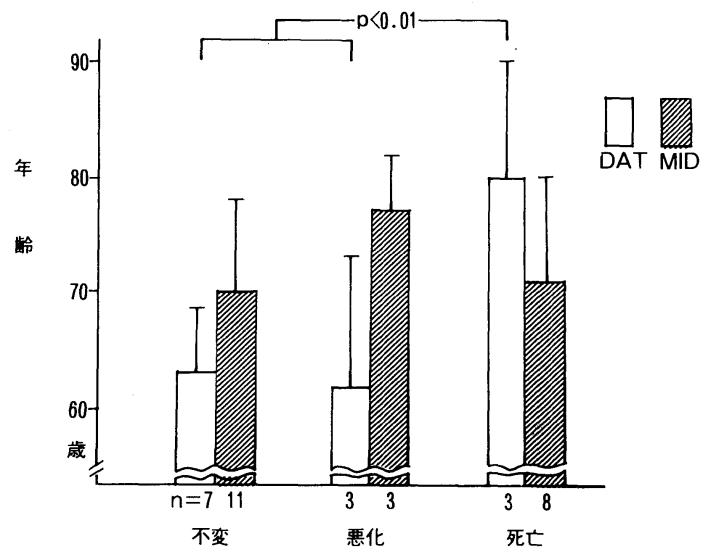

図 2 痴呆の病型別にみた年齢と予後

から受診時末での罹病期間と予後について検討した が, 各群について有意差はみられなかった。尚, DAT, MID 各 1 例ずつ剖検により病理学的に診断が確認さ れた。

2) 初診時の痴呆の程度と予後：DATに抢ける初 診時長谷川式簡易知的機能検查スケール得点は，不変

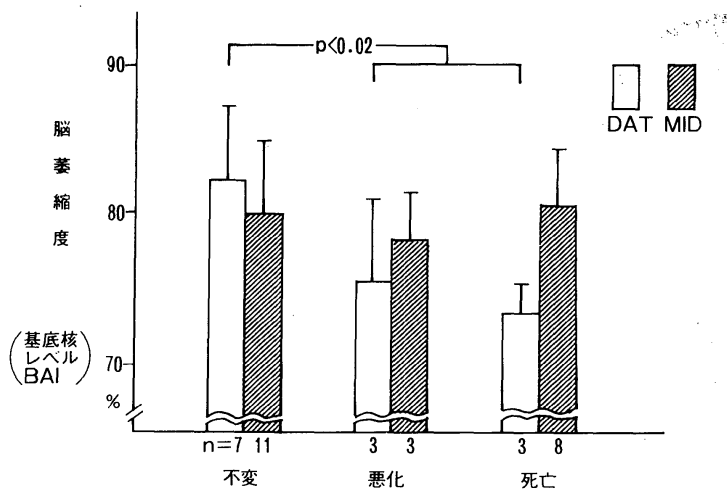

図 3 痴呆の病型別にみた脳萎縮度と予後

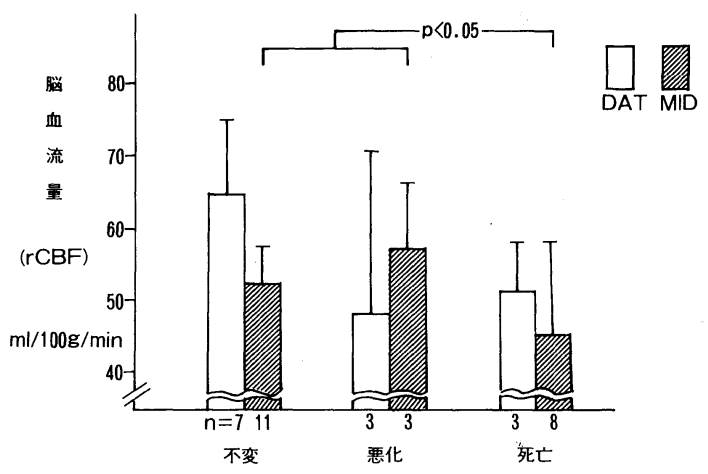

図 4 痴呆の病型別にみた全脳平均脳血流量と予後 

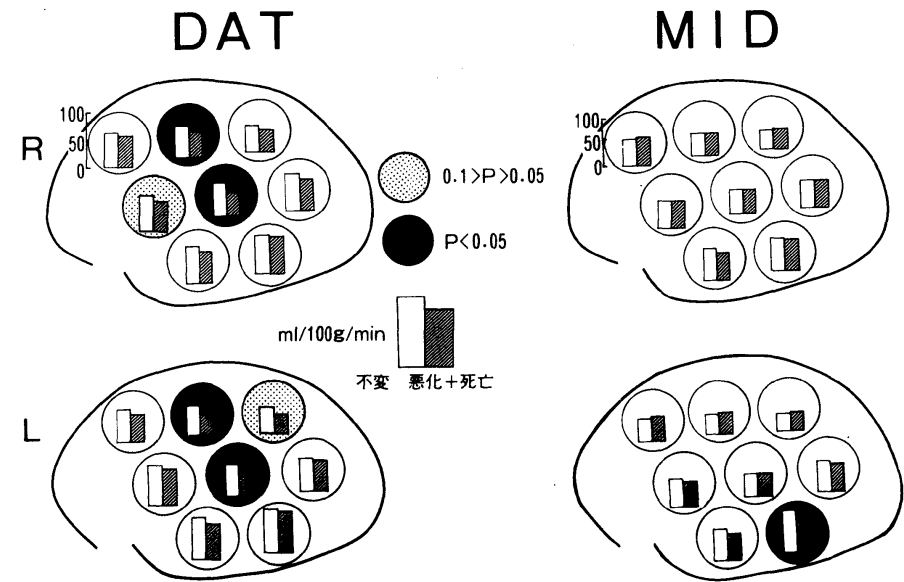

図 5 痴呆の病型別にみた局所脳血流量と予後

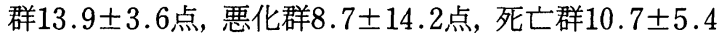
点であり有意差はみられなかった.ADL スコアにおい ても同様の結果であった. MID に执いても長谷川式得 点は不変群 $17.3 \pm 6.3$ 点, 悪化群 $14.3 \pm 4.5$ 点, 死亡群

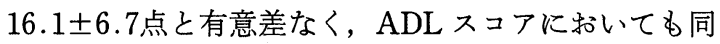
様であった。

3）脳萎縮と予後：基底核レベルの BAI を指標とし た脳萎縮度では図 3 に示すように, DAT に拈いては 悪化群十死亡群は不变群に比し有意に脳萎縮が強く認 められた。一方，MID に扣いては 3 群間に有意差はみ られなかった。

4）局所脳血流量と予後: 初診時脳血流量では表 1 に示す様に MID 群が平均 $50.4 \pm 9.8 \mathrm{~m} l / 100 \mathrm{~g} / \mathrm{min}$ と $\mathrm{DAT}$ 群の $57.5 \pm 15.4 \mathrm{ml} / 100 \mathrm{~g} / \mathrm{min}$ に比し有意に低 下していた。一方, 各群における予後との関係では図 4 に示すように, DAT では 3 群間に有意差はみられ なかったが, MIDに打いては死亡群で $45.0 \pm 13.1 \mathrm{~m} l /$ $100 \mathrm{~g} / \mathrm{min}$ と, 生存群 (不変十死亡群) の $53.4 \pm 5.9 \mathrm{~m} l /$ $100 \mathrm{~g} / \mathrm{min}$ に比し有意な脳血流量の低下が認められ た。この低下を局所別に検討したものが図 5 である。 DAT では死亡群の両側頭頂葉で生存群に比し有意な 脳血流量低下が認められたが, MIDに打いては左後頭 葉に若干の差を認めるのみで, 特徵的な pattern は示 さなかった。

脳血流量と脳萎縮度の予後に対する関係を同時に示 したものが図 6 である. DAT においては, 悪化十死亡 群に招ける脳萎縮の進行が, また MIDに招いては死 亡群における脳血流低下が特徵的な所見として示され ている.
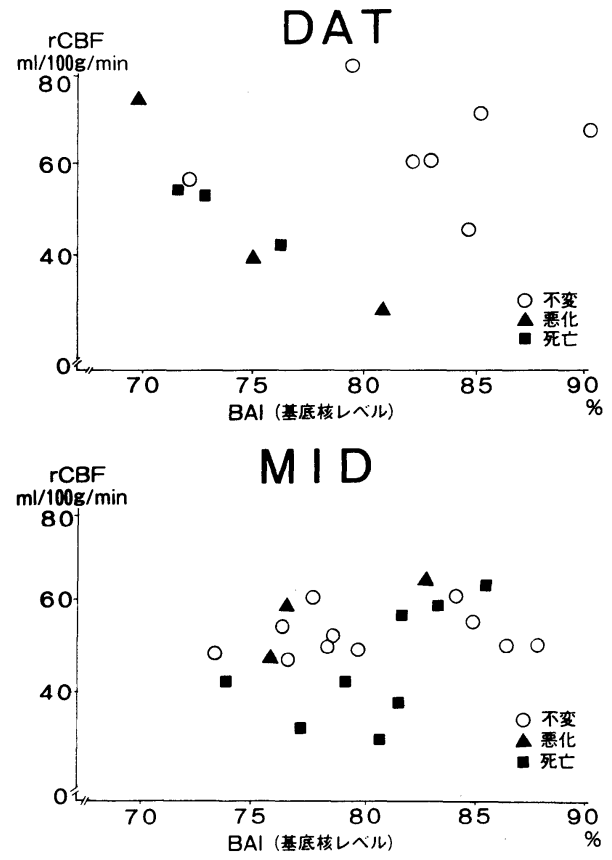

図 6 痴呆の病型別にみた脳血流量, 脳萎縮と予後と の関係

\section{考案}

痴呆患者の予後に関する報告としては Goldfarb ${ }^{1)}$ 64 歳以上の施設老人 1,280 名を対象として 7 年間の追 跡調查を行い 5 年後では中等度痴呆例で死亡率は $78 \%$, 高度痴呆例で $90 \% ， 7$ 年後ではそれぞれ $88 \%$, $94 \%$ と全体の死亡率 5 年後 $73 \%, 7$ 年後 $82 \%$ に比して 痴呆が高度となるに従い死亡率が高くなるとしてい 
る. Nielsen $ら^{21}$ は地域在住の65歳以上の994名につい て15年間の調查を行い, 生存期間は高度痴呆で平均 2.6 年, 中等度痴呆で 4.8 年と精神疾患のない例の 7.6 年に 比し有意に短いとしている。また $\mathrm{Kay}^{3}$ は精神病院に 打ける老年痴呆 41 名, 脳血管性痴呆 41 名の 5 年後の死 亡率は $82 \%$ であり非痴呆群の $33 \%$ に比し有意に高かっ たとしている。我が国に打ける痴呆の追跡調査として は長谷川ら4)の報告をみるのみであるが, それによれ ば地域在住老人 433 名についての 5 年後の予後調査を 行い老化性痴呆の死亡率は $87.4 \%$ と非老化性痴呆 $37.5 \%$ に比べ有意に高く, 高度痴呆, 失禁, 寝たきり などの要因により死亡率が増加すると述べている。ま た，老年痴呆之脳血管性痴呆に分けて検討した結果で は予後に大きな差はみられなかったとしている。

今回の我々の検討は平均 18 力の比較的短い追跡期 間であったが，DATで23.1\%，MID で36.4\%の死亡 率とMIDで高率であった。 Barcleyらは199例の DAT, 69例の MID, 43例の混合性痴呆について 5 年以 上追跡し発症よりの $50 \%$ 生存期間は DAT の 8.1 年に 対し MIDでは6.7年と短かったとして抒り, 我々の結 果と一致していた.

これまでの報告では痴呆が高度になるにつれ死亡率 も上昇するとされているが，今回の我々の検討では DAT, MID 共痴呆の程度と死亡率との間に関係はみ られなかった。これは対象とした患者が初診時独歩可 能な初期から中期の患者であり寝たきり, 失禁などの 重症例を含んでいないためと考劣られる。

痴呆患者に抢ける脳萎縮に関しては病型によりその 機序が異なっていると考光られる. Ladurner ら ${ }^{10)}$ 及び 我々の検討によればMIDに打いては, 脳萎縮の進行 と知能の低下は同時に進行するが，DAT に扮いては Damasio ら ${ }^{11)}$, Melamed ら ${ }^{12)}$ の報告のごとくMID 程 には知能と脳萎縮は相関しないようである。一方, 今 回の検討で得られたDAT の悪化, 死亡群に扮ける脳 萎縮の有意な進行はDATに和ける予後を判定する上 での一つの指標となりらると思われる。

また，痴呆患者に拈ける脳血流量に関してHachin$\mathrm{ski}^{8}{ }^{8}{ }^{133} \mathrm{Xe}$ 吸入法により検討した結果, DAT は正常 と変らないが MID では明らかに低下していたとし， その低下は痴呆の程度ともよく相関したとしている。 脳血流量の変化を追跡した報告として, Barclay $\left.{ }^{13}\right)$ は 23例の DAT で脳血流量の変化率は $-0.60 \mathrm{~m} l / 100 \mathrm{~g} /$ $\mathrm{min} /$ 月, 8 例の血管性痴呆でー $0.43 \mathrm{~m} l / 100 \mathrm{~g} / \mathrm{min} /$ 月 といずれも正常例の $-0.013 \mathrm{ml} / 100 \mathrm{~g} / \mathrm{min} /$ 月に比べ
明らかに血流低下の促進がみられるとしている。 Rogers ${ }^{6)}$ は181例のボランティアを 7 年間追跡し, 6 例の DAT と10例の MID の発症をみ, そのらち MID では発症以前より脳血流量低下がみられるが DAT では発症後に急速に低下するとしている，今回 の結果では MID に打いては高度の脳血流低下は予後 不良を示唆していた。一方, DAT では全脳平均血流量 では有意差はみられなかったが，予後不良群（悪化十 死亡）で両側頭頂葉に拈ける局所脳血流量の低下が示 されたことは興味ある点である。しかしその意味づけ については今後の検討が必要であると考觉られる。

以上の結果より定量的な脳萎縮の評価, 脳血流量の 測定は痴呆の病型の診断のみならず予後の推定にも有 用であることが示された。

\section{文献}

1) Goldfarb AI: Predicting motality in the institutionalized aged. Arch Gen Psychiat $21: 172$ $-176,1969$.

2) Nielsen J, Homma A, B-Henriksen: Follow-up 15 years after a geronto-psychiatric prevance study. Conditions concerning death, cause of death, and life expancy in relation to psychiatric diagnosis. J Geront 32: 554-561, 1977.

3) Kay DWK: Outcome and cause of death in mental disorders of old age : A longterm followup of functional and organic psychoses. Acta Psychiat Scand $38: 249-276,1962$.

4）長谷川和夫, 本間 昭, 尹 美淑ら：老化性痴呆の 追跡調查一 5 年後の予後. 日老会誌 $17: 630$ $-637,1980$.

5) Barclay LL, Zemcov A, Blass JP, Sansone J : Survival in Alzheimer's disease and vascular dementias. Neurology $35: 834-840,1985$.

6) Rogers RL, Meyer JS, Mortel KF, Mahurin RK, Judd BW : Decreased cerebral blood flow precedes multi-infarct dementia, but follows senile dementia of Alzheimer type. Neurology 36 : $1-6,1986$.

7) 岡田和悟, 小林祥泰, 山口修平, 木谷光博, 恒松徳 五郎：穿通枝領域多発梗塞性痴呆における CT 所 見と局所脳循環。脳卒中 $7: 418-424,1985$.

8) Hachinski VL, Iliff LD, Zilhka E, et al: Cerebral blood flow in dementia. Arch Neurol 32 : 632-637, 1975. 
9）木谷光博, 小林祥泰, 山口修平, 勝部知子, 岡田和 悟, 村田昭博, 恒松德五郎：CT scanによる大脳 の加齢性萎縮の検討一Digitizerによる断面積比 を用いた一。 CT 研究 6:659-666, 1984.

10) Ladurner G, Sager WD, Flooh E: Computertomography and vascular (Multiinfarct) dementia: A qualitative and quantitativve investigation. The aging brain (edited by Hoyer S), Springer-Verlag Berlin heidelberg, 1982.

11) Damasio H, Esliger P, Damasio AR, Rizzo M, Huang HK, Demeter S: Quantitative computed tomographic analysis in the diagnosis of dementia. Arch Neurol 40 : 715-719, 1983.

12) Melamed E, lavy S, Siew F, Bentin S, Cooper

$G$ : Correlation between regional cerebral blood flow and brain atrophy in dementia. Combined study with ${ }^{133} \mathrm{Xe}$ inhalation and computed tomography, J Neurol Neurosurg Psychiatry $41: 894-899,1978$.

13) Barclay L, Zecov A, Blass JP, McDowell F: Rates of decrease of cerebral blood flow in progressive dementias. Neurology 34:1555 -1560, 1984.

Abstract

\title{
The Relationship Between Prognosis, Regional Cerebral Blood Flow (rCBF) and Brain Atrophy in Dementia
}

\author{
Kazunori Okada, Shoutain Kobayashi, Shuhei Yamaguchi, Mituhiko Kitani, \\ Satao Arimoto, Kouichi Shimode and Tokugoro Tsunematsu
}

The prognosis of dementia has generally been regarded as poor, and its five year motality rate is reported to be about $80 \%$. Recently, Barclay and Rogers have reported that the pattern of $\mathrm{rCBF}$ reduction is different between multiinfarct dementia (MID) and dementia of the Alzheimer type (DAT). We studied the relationship between prognosis, brain atrophy and cerebral blood flow in thirty-five demented patients (22 MID and 13 DAT) by using bi-dimensional brain atrophy indices and the ${ }^{133} \mathrm{Xe}$ inhalation method. The mean follow-up period was 18 months. MID group showed signifcantly lower rCBF than DAT group at start point. Three patients of DAT and eight patients of MID were died. In MID, two patients died because of recurrent cerebrovascular accident, and others died because of infectious disease, renal

The 3rd Internal Medicine, Shimane Medical University failure, and unknown causes. In DAT, patients were died because of infectious disease, cardiac failure, and sudden death. The rCBF reduction in the bilateral parietal regions related with poor prognosis of DAT. In MID, the reduction of $\mathrm{rCBF}$ were more marked and diffuse pattern than that of DAT and patients who showed lower $\mathrm{rCBF}$ had poor prognosis. Motality rate was getting higher with advancing brain atrophy in DAT, but MID showed no such relationship. These results indicated that the quantitative evaluation of the brain atrophy and rCBF measurement may be useful not only to diagnose the type of dementia but also to suppose the prognosis of the demented patients.

key words: brain atrophy, cerebral blood flow, multiinfarct dementia (MID), dementia of the Alzheimer type (DAT), prognosis in dementia

(Jpn. J. Geriat 24: 284-288, 1987) 